Molecules 2005, 10, 394-400

molecules

ISSN 1420-3049

http://www.mdpi.org

\title{
An Aromatic Iodination Method, with Iodic Acid Used as the Only Iodinating Reagent ${ }^{\dagger}$
}

\section{Barbara Krassowska-Swiebocka, Grazyna Prokopienko and Lech Skulski*}

Chair and Laboratory of Organic Chemistry, Faculty of Pharmacy, Medical University, Banacha 1, PL 02-097 Warsaw, Poland

$\dagger$ This short paper was presented at the Eighth Electronic Conference on Synthetic Organic Chemistry (ECSOC-8, http://www.mdpi.net/ecsoc-8), November 1-30, 2004 (paper A023).

* To whom the correspondence should be addressed; E-mail: lechskulski@yahoo.com; Tel./Fax: +(48) 22-5720643

Received: 8 November 2004; in revised form: 28 January 2005 / Accepted: 29 January 2005 / Published: 28 February 2005

\begin{abstract}
Benzene, halobenzenes, and a number of more or less deactivated arenes, including nitrobenzene, readily reacted in anhydrous $\mathrm{HIO}_{3} / \mathrm{AcOH} / \mathrm{Ac}_{2} \mathrm{O} /$ conc. $\mathrm{H}_{2} \mathrm{SO}_{4}$ mixtures to probably give $\mathrm{ArIO}_{2}$ intermediates or other hypervalent species (not isolated). The final reaction mixtures were poured into excess aq. $\mathrm{Na}_{2} \mathrm{SO}_{3}$ solution $(a$ reductant) to give the purified iodinated products in $39-83 \%$ yields.
\end{abstract}

Keywords: Arenes, iodoarenes, aromatic iodination, iodic acid as reactant and iodinating agent

\section{Introduction}

In 1892 Meyer and Wachter [1], in describing iodosylbenzoic acid, the first iodosylarene, included there the following passage: "Ferner ist zu prüfen, ob man durch Behandlung von aromatischen Substanzen mir Schwefelsäure und Jodsaüre, - $\mathrm{JO}_{2} \mathrm{OH}$, entsprechend der Reaction der Salpetersäure, $\mathrm{NO}_{2} \mathrm{OH}$, - Verbindungen mit der Gruppe $-\mathrm{JO}_{2}$ erhalten kann. Wir können vorläufig nur mittheilen, dass Benzol beim Zusammenbringen mit Jodsäure und Schwefelsäure äusserst heftig reagirt und auf Zusatz von Wasser einen festen Körper abscheidet, welchen wir not näher untersuchen werden“. It 
means [1] that they had suggested the following reaction to occur, but this idea was not exploited by them further on:

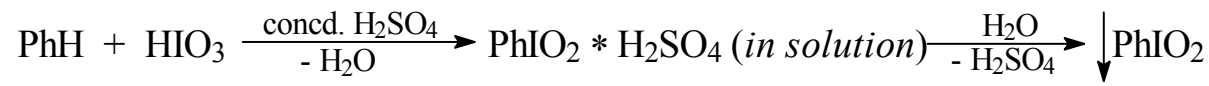

$$
\begin{aligned}
& \text { Iodylbenzene sulfate [2] }
\end{aligned}
$$

In 1935 Masson and co-workers [2] had however established that benzene derivatives and $\mathrm{HIO}_{3}$ in sulfuric acid readily formed diaryliodonium salts in high yield; later on, their initial discovery was extended considerably [3]:

$$
\mathrm{I}^{+3}+2 \mathrm{ArH} \longrightarrow 2 \mathrm{H}^{+}+\mathrm{Ar}_{2} \mathrm{I}^{+} \text {or alternatively } \mathrm{IO}^{+}+2 \mathrm{ArH} \longrightarrow \mathrm{H}_{2} \mathrm{O}+\mathrm{Ar}_{2} \mathrm{I}^{+}
$$

Some experimental evidence was given that a primary deoxidation of the iodic acid to the iodous stage by a fraction (ca. 15\%) of the aromatic reagent, $\mathrm{ArH}$ (which is thereby converted into an openchain unsaturated substance), was followed by the direct interaction of the iodous acid and the aromatic reagent to give the diaryliodonium salts; aryl iodides were also formed there as side products, and the production of $\mathrm{CO}_{2}$ was observed. Hence, the above reactions had a very complex mechanism, the details of which are still not clear.

Beringer and co-workers $[4 \mathrm{a}, 5]$ coupled some reactive aromatic compounds (benzene, toluene, mesitylene, $t$-butylbenzene, $n$-dodecylbenzene, cyclohexylbenzene, anisole, acetanilide, and succinanil) with $\mathrm{KIO}_{3}$ in $\mathrm{AcOH} / \mathrm{Ac}_{2} \mathrm{O} / \mathrm{H}_{2} \mathrm{SO}_{4}$ mixtures to obtain the respective symmetrical diaryliodonium bisulfates:

$$
2 \mathrm{ArH}+\mathrm{IO}_{3}^{-}+2 \mathrm{H}_{2} \mathrm{SO}_{4}+2 \mathrm{Ac}_{2} \mathrm{O} \longrightarrow \mathrm{Ar}_{2} \mathrm{I}^{+}+2 \mathrm{HSO}_{4}^{-}+4 \mathrm{AcOH}+[\mathrm{O}]
$$

If the temperature of reaction mixtures was not kept below $15{ }^{\circ} \mathrm{C}$ during the addition of the sulfuric acid and for some hours thereafter, a vigorous, exothermic reaction was observed. They suggested that in such instances the iodate was effecting a deep-seated oxidation of the aromatic compounds. By anion metatheses of the diaryliodonium bisulfates, they isolated the corresponding chlorides, bromides, iodides, and one nitrate in 9-88\% yields. Diaryliodonium salts are fairly resistant towards the action of cold aq. $\mathrm{Na}_{2} \mathrm{SO}_{3}$ solutions; only their prolonged treatment with excess sodium sulfite in boiling water can effectively split them up as follows [4]: $\mathrm{Ar}_{2} \mathrm{I}^{+} \mathrm{X}^{-}+\mathrm{Na}_{2} \mathrm{SO}_{3} \rightarrow \mathbf{A r I}+\mathrm{ArSO}_{3} \mathrm{Na}+\mathrm{NaX}$.

In 1969 Ciustea and Panescu [6] briefly reported that the treatment of halobenzenes, benzoic acid, nitrobenzene or benzamide, dissolved in $\mathrm{H}_{2} \mathrm{SO}_{4}, \mathrm{H}_{3} \mathrm{PO}_{4},\left(\mathrm{CH}_{3} \mathrm{CO}\right)_{2} \mathrm{O}, \mathrm{CH}_{3} \mathrm{COOH}, \mathrm{H}_{2} \mathrm{O}$ or in sulfuric acid with an amount of water added, with $\mathrm{HIO}_{3}$, possibly resulted in the formation of the respective iodylarenes, $\mathrm{ArIO}_{2}$, or 3,5-diiodylbenzamide; these compounds can next be reduced to the corresponding aryl iodides or 3,5-diiodobenzamide. This short communication, with no experimental details, analytical data or physico-chemical support, was never followed up either then or after 1969 in a more detailed experimental paper [7, p. 1355].

$$
\mathrm{ArH}+\mathrm{HIO}_{3}+\mathrm{H}_{2} \mathrm{SO}_{4}\left(\mathrm{H}_{2} \mathrm{O}\right) \longrightarrow \mathrm{ArIO}_{2} \stackrel{\text { reduction }}{\longrightarrow} \text { ArI }
$$

Taking into account all the aforementioned literature information, in fact all very controversial and potentially misleading, in 2003 we endeavored in our laboratory to carry out some preliminary experiments on the possibility of preparing iodylarenes, $\mathrm{ArIO}_{2}$, from the corresponding arenes. Rudzki [8] on reacting chlorobenzene with $\mathrm{HIO}_{3}$ in anhydrous $\mathrm{Ac}_{2} \mathrm{O}$ /concd $\mathrm{H}_{2} \mathrm{SO}_{4}$ mixtures, under widely varied reaction conditions, obtained in the best possible manner 4-chloroiodylbenzene, $4-\mathrm{ClC}_{6} \mathrm{H}_{4} \mathrm{IO}_{2}$, 
albeit in only $18 \%$ crude yield. In contrast, when he reacted chlorobenzene for 10 hours with $\mathrm{HIO}_{3}$ in hot $\left(80^{\circ} \mathrm{C}\right) 75 \%(\mathrm{v} / \mathrm{v}) \mathrm{H}_{2} \mathrm{SO}_{4}$, he isolated bis(4-chlorophenyl)iodonium sulfate in $63 \%$ yield; 1-chloro4-iodobenzene (30\%) was isolated there as a side product. Simultaneously, we have established [9] that benzene, halobenzenes and some deactivated arenes (excluding however nitrobenzene) readily reacted in anhydrous $\mathrm{NaIO}_{4} / \mathrm{AcOH} / \mathrm{Ac}_{2} \mathrm{O} /$ concd $\mathrm{H}_{2} \mathrm{SO}_{4}$ mixtures. Next, the final reaction mixtures were poured into excess aq. $\mathrm{Na}_{2} \mathrm{SO}_{3}$ solution (a reductant) to give the purified iodinated products in $27-88 \%$ yields. This is a quite novel approach to aromatic iodination:

$\mathrm{ArH}+\mathrm{NaIO}_{4} \underset{\mathrm{AcOH} / \mathrm{Ac}_{2} \mathrm{O} / \text { concd. } \mathrm{H}_{2} \mathrm{SO}_{4}}{-\mathrm{NaHSO}_{4}}\left[\mathrm{ArIO}_{3}\right]($ not isolated $) \underset{\text { reduction }}{\stackrel{\text { aq. } \mathrm{Na}_{2} \mathrm{SO}_{3}}{\longrightarrow}}$ ArI

where $\left[\mathrm{ArIO}_{3}\right]$ are hypothetical transient periodylarenes, not isolable in spite of many attempts.

So, we have decided to carry out the iodinating reactions as follows:

$\mathrm{ArH}+\mathrm{HIO}_{3}+\mathrm{Ac}_{2} \mathrm{O} \stackrel{\mathrm{AcOH} / \mathrm{Ac}_{2} \mathrm{O} / \mathrm{concd} . \mathrm{H}_{2} \mathrm{SO}_{4}}{\longrightarrow} 2 \mathrm{AcOH}+\left[\mathrm{ArIO}_{2} * \mathrm{H}_{2} \mathrm{SO}_{4}\right]$ (not isolated)

$\left[\mathrm{ArIO}_{2} * \mathrm{H}_{2} \mathrm{SO}_{4}\right]$ or other hypervalent iodine species + excess aq. $\mathrm{Na}_{2} \mathrm{SO}_{3} \underset{39-83 \%}{\stackrel{\text { reduction }}{\longrightarrow}}$ ArI

Our final results presented in the Table 1 do confirm that this approach to aromatic iodination is quite successful and promising.

Table 1. Iodinated pure products obtained from some arenes, their yields, elemental analyses, and melting or boiling points (uncorrected).

\begin{tabular}{|c|c|c|c|c|c|}
\hline Substrate & Product & $\begin{array}{c}\text { Yield, } \\
(\%)\end{array}$ & $\begin{array}{l}\text { Analysis, \% I } \\
\text { calcd (found) }\end{array}$ & $\mathbf{M p}\left({ }^{\circ} \mathbf{C}\right) / \mathbf{S}^{\mathrm{a})}$ & $\begin{array}{c}\text { Lit, } \mathbf{m p}\left({ }^{\circ} \mathrm{C}\right) \\
{[10]}\end{array}$ \\
\hline $\mathrm{C}_{6} \mathrm{H}_{6}$ & $1,4-\mathrm{I}_{2} \mathrm{C}_{6} \mathrm{H}_{4}$ & 60 & $76.95(76.5)$ & $127-128 / \mathbf{E}$ & 129 \\
\hline PhI & $1,4-\mathrm{I}_{2} \mathrm{C}_{6} \mathrm{H}_{4}$ & 58 & $76.95(77.2)$ & $127.5-129 / \mathbf{E}$ & 129 \\
\hline $\mathrm{PhBr}$ & 4- $\mathrm{BrC}_{6} \mathrm{H}_{4} \mathrm{I}$ & 71 & $44.86(44.8)$ & $95-97 / \mathbf{E}$ & 92 \\
\hline $\mathrm{PhCl}$ & 4- $\mathrm{ClC}_{6} \mathrm{H}_{4} \mathrm{I}$ & 39 & $53.22(52.7)$ & $54-56 / \mathbf{E}$ & 57 \\
\hline $\mathrm{PhNO}_{2}$ & $3-\mathrm{IC}_{6} \mathrm{H}_{4} \mathrm{NO}_{2}$ & 82 & $50.96(50.4)$ & $35-37 / \mathbf{P}$ & $35-36$ \\
\hline $\mathrm{PhCOOH}$ & $3-\mathrm{IC}_{6} \mathrm{H}_{4} \mathrm{COOH}$ & 67 & $51.17(51.2)$ & $189-190 / \mathbf{C}$ & 188-189 \\
\hline PhCOOMe & 3- $\mathrm{IC}_{6} \mathrm{H}_{4} \mathrm{COOMe}$ & 59 & $48.43(48.5)$ & $55-56 / \mathbf{E W}$ & $54-55$ \\
\hline PhCOOEt & 3- $-\mathrm{IC}_{6} \mathrm{H}_{4} \mathrm{COOEt}$ & 51 & $45.97(45.8)$ & bp $170-172 / 29$ & bp $150 / 15$ \\
\hline 4- $\mathrm{MeC}_{6} \mathrm{H}_{4} \mathrm{COOH}$ & 3-I-4- $\mathrm{MeC}_{6} \mathrm{H}_{3} \mathrm{COOH}$ & 78 & $48.43(48.2)$ & $211-212 / \mathbf{C}$ & $210-212$ \\
\hline $4-\mathrm{MeC}_{6} \mathrm{H}_{4} \mathrm{NO}_{2}$ & 3-I-4- $\mathrm{MeC}_{6} \mathrm{H}_{3} \mathrm{NO}_{2}$ & 40 & $48.25(47.9)$ & $52-54 / \mathbf{E}$ & $54-56$ \\
\hline $4-\mathrm{MeOC}_{6} \mathrm{H}_{4} \mathrm{NO}_{2}$ & 3-I-4- $\mathrm{MeOC}_{6} \mathrm{H}_{3} \mathrm{NO}_{2}$ & 83 & $45.51(45.1)$ & $94-96 / \mathbf{E}$ & 97 \\
\hline $2-\mathrm{O}_{2} \mathrm{NC}_{6} \mathrm{H}_{4} \mathrm{NHCOCH}_{3}$ & $4-\mathrm{I}-2-\mathrm{O}_{2} \mathrm{NC}_{6} \mathrm{H}_{3} \mathrm{NHCOCH}_{3}$ & 52 & $41.50(41.5)$ & $110-112 / \mathbf{E W}$ & 112 \\
\hline
\end{tabular}

a) Solvents used for crystallization: $\mathbf{C}-\mathrm{CCl}_{4} ; \mathbf{E}-\mathrm{EtOH} ; \mathbf{P}-$ petroleum ether; $\mathbf{E W}-\mathrm{EtOH} / \mathrm{H}_{2} \mathrm{O}$

\section{Results and Discussion}

For benzene (which was only diiodinated), three halobenzenes and eight deactivated arenes, including nitrobenzene (Table 1), we carried out the iodinating reactions according to the stoichiometry shown in Eq. 6, where: $\left[\mathrm{ArIO}_{2} * \mathrm{H}_{2} \mathrm{SO}_{4}\right]$ are the assumed iodine $(V)$ intermediates, 
possibly strongly admixed with $\mathrm{ArI}\left(\mathrm{OSO}_{3} \mathrm{H}\right)_{2}$; it is known that amphoteric iodylarenes freely form salts with strong mineral acids, and the hygroscopic sulfate $\mathrm{PhIO}_{2} \cdot \mathrm{H}_{2} \mathrm{SO}_{4}\left(\mathrm{mp} 127^{\circ} \mathrm{C}\right)$ was analyzed and examined [2].

Thus, iodic acid and chosen arenes, $\mathrm{ArH}$, were suspended in cooled $\left(5^{\circ} \mathrm{C}\right)$ anhydrous $\mathrm{AcOH} / \mathrm{Ac}_{2} \mathrm{O}$ mixtures, and then a large excess of concd. (95\%) sulfuric acid was slowly added dropwise, with vigorous stirring, to the reaction mixtures, while keeping the temperature below $10{ }^{\circ} \mathrm{C}$. The strongly acidified reaction mixtures were then stirred for one hour in an ice-water bath, next for one hour at room temperature and then for 2 hours at $45-50{ }^{\circ} \mathrm{C}$. We have established that somewhat better yields are achieved when the reaction mixtures were finally left overnight at room temperature. The final reaction mixtures were quenched by pouring into stirred ice-water containing a previously dissolved excess of $\mathrm{Na}_{2} \mathrm{SO}_{3}$ (a reductant), Eq. 7. The oily or solid crude products that precipitated out were typically isolated and purified (see the Experimental) to give the purified monoiodinated products in $39-83 \%$ yields, except in the case of 1,4-diiodobenzene, which was obtained in $60 \%$ yield (Table 1). The chemical structures of the purified products were next confirmed by their melting or boiling points, all close to those reported in the literature [10], elemental analyses (\%I), and comparison of the ${ }^{1} \mathrm{H}$ and ${ }^{13} \mathrm{C}$ NMR spectra (not reported here) with the corresponding spectra of authentic samples. Their homogeneities were checked by TLC.

We have also tried to isolate the purported iodine $(V)$ intermediates, i.e. $\mathrm{ArIO}_{2}$, by pouring the final reaction mixtures into ice-water $\left(\mathrm{ArIO}_{2} \cdot \mathrm{H}_{2} \mathrm{SO}_{4}\right.$ is readily hydrolyzable [2]). However, the crude yields of $\mathrm{ArIO}_{2}$ thus obtained were usually lower than $20 \%$, and the crude $\mathrm{ArIO}_{2}$ had to be recrystallized from boiling water at least once - which lowered the yields further. The best result was obtained with bromobenzene that afforded 1-bromo-4-iodylbenzene in $40 \%$ crude yield (see the Experimental). Hence, these attempts were deemed unworthy of further study. It should be pointed out that we previously devised in our laboratory two easy and effective methods of preparing $\mathrm{ArIO}_{2}$ from ArI using $\mathrm{NaIO}_{4}$ as the oxidant, acting either in boiling water [11] or in boiling $30 \%(\mathrm{v} / \mathrm{v})$ aq. acetic acid [12]. The crude yields of $\mathrm{ArIO}_{2}$ thus obtained were good to excellent, while the snow-white crude products had a $98-99 \%$ purity, established iodometrically.

We present in this paper an easy and effective approach to the aromatic iodination, which allows one to obtain iodoarenes, in good yields, from halobenzenes and several deactivated arenes, including nitrobenzene; cf. Ref. [9]. The transient protonated iodic acid, $\mathrm{O}_{3} \mathrm{I}^{+} \mathrm{H}_{2}$, was the sole iodinating agent present, capable of forming the stable $\mathrm{C}$-I bond in the starting arenes, which is preserved after the reduction with excess aq. $\mathrm{Na}_{2} \mathrm{SO}_{3}$ solution to afford the final mono- or diiodinated arenes (Table 1). However, activated arenes, e.g. anisole, acetanilide, $N, N$ - dimethylaniline, etc., were easily oxidized under the given reaction conditions to form some tarry products, which could not be purified in spite of our numerous attempts.

Note added in proof. For comparison, also $\mathrm{NaBrO}_{3}$ is a powerful brominating agent for deactivated aromatics. Addition of a strong acid into a stirred aq. solution, or slurry, of the substrate and $\mathrm{NaBrO}_{3}$ at 40-100 ${ }^{\circ} \mathrm{C}$, leads to the decomposition of the bromate ions and production of the active brominating species. Substrates such as nitrobenzene, benzoic acid, and benzaldehyde were specifically brominated in $85-98 \%$ yields. The reaction is especially useful for the bromination of disubstituted benzenes, such as $4-\mathrm{FC}_{6} \mathrm{H}_{4} \mathrm{NO}_{2}$ or $4-\mathrm{FC}_{6} \mathrm{H}_{4} \mathrm{COOH}$. Dinitrobenzenes and nitrobenzoic acids did not undergo bromination at all. See Ref. 13 . 


\section{Experimental}

\section{General}

All the reagents and solvents were commercial (Aldrich) and were used without further purification. The melting or boiling points of pure iodinated products (Table 1) are uncorrected. Elemental microanalyses (\%I) were performed at the Institute of Organic Chemistry, the Polish Academy of Sciences in Warsaw. ${ }^{1} \mathrm{H}$ - and ${ }^{13} \mathrm{C}$-NMR spectra (not shown here) were recorded at room temperature, in $\mathrm{CDCl}_{3}$ solutions, with a Bruker Avance DMX $400 \mathrm{MHz}$ spectrometer; sometimes, in order to get better assignments, also ${ }^{1} \mathrm{H}-{ }^{13} \mathrm{C}$ correlation spectra were recorded. The spectra confirmed the chemical structures of the purified iodinated products (Table 1).

\section{Optimized Preparations of Iodoarenes from Arenes}

Iodic acid (3.25 g, $20 \mathrm{mmol})$ was suspended in a mixture made of glacial AcOH $(20 \mathrm{~mL})$ and acetic anhydride $(10 \mathrm{~mL})$, then an appropriate arene $(20 \mathrm{mmol})$ was added with stirring. The stirred mixture was cooled to ca. $5{ }^{\circ} \mathrm{C}$, and concd. $(95 \%)$ sulfuric acid $(10 \mathrm{~mL}$, ca. $0.2 \mathrm{~mol})$ was very slowly added dropwise while keeping the temperature below $10{ }^{\circ} \mathrm{C}$. The reaction mixtures were stirred for $1 \mathrm{~h}$ in an ice-water bath, then for $1 \mathrm{~h}$ at r.t. and next for $2 \mathrm{~h}$ at $45-50{ }^{\circ} \mathrm{C}$. The stirring was continued overnight at r.t. The final reaction mixtures were poured into ice-water $(100 \mathrm{~g})$ containing previously dissolved $\mathrm{Na}_{2} \mathrm{SO}_{3}$ (a reductant, $5 \mathrm{~g}$ ). After a few hours, the precipitated crude solid products were collected by filtration, washed well with cold water until the filtrates were neutral, dried preliminarily by suction, and next air-dried in the dark. They were recrystallized from appropriate organic solvents (Table 1) to give the purified solid iodinated products. If the crude iodinated products were oily or semisolid, they were extracted with $\mathrm{CHCl}_{3}(3 \times 20 \mathrm{~mL})$, the combined extracts were dried over anh. $\mathrm{MgSO}_{4}$, filtered, the solvent was distilled off, and the residues were fractionated under vacuum to give the purified liquid iodinated products (Table 1). The purified iodoarenes should be preserved in the dark, preferably at $0-5{ }^{\circ} \mathrm{C}$. Note: When benzene was diiodinated as above to give pure 1,4-diiodobenzene, only half of its amount, i.e. $10 \mathrm{mmol}$, was added to the reaction mixture.

\section{Possibly Optimized Preparation of 1-Bromo-4-iodylbenzene from Bromobenzene}

Iodic acid (5.28 g, $30 \mathrm{mmol})$ was suspended in a mixture made of glacial $\mathrm{AcOH}(10 \mathrm{~mL})$ and $\mathrm{Ac}_{2} \mathrm{O}$ $(5 \mathrm{~mL})$, then bromobenzene $(4.71 \mathrm{~g}, 30 \mathrm{mmol})$ was added with stirring. Concd. $(95 \%) \mathrm{H}_{2} \mathrm{SO}_{4}(2 \mathrm{~mL})$ was very slowly added dropwise with vigorous stirring, keeping the temperature below $50{ }^{\circ} \mathrm{C}$. Next, the stirring was prolonged within $2 \mathrm{~h}$ at ambient temperature. The final reaction mixture was poured into ice-water, and the precipitated oily product slowly solidified. The precipitate was collected by filtration, washed with a little ice water, then with acetone. The colorless final product, obtained in $40 \%$ crude yield, decomposed at $235{ }^{\circ} \mathrm{C}$ with detonation, lit. [12] $\mathrm{mp} 236{ }^{\circ} \mathrm{C}$ with detonation. 


\section{References and Notes}

1. Meyer, V.; Wachter, W. Ueber Jodosobenzoësäure. Ber. Dtsch. Chem. Ges. 1892, 25, 2632-2635. The German passage in the text can be translated as follows: "Next, it has to be checked out whether the reaction of aromatic compounds with sulfuric acid and iodic acid, $\mathrm{IO}_{2} \mathrm{OH}$, corresponding to the reaction with nitric acid, $\mathrm{NO}_{2} \mathrm{OH}$, can afford the respective compounds substitued by the $-\mathrm{IO}_{2}$ group. We can only preliminarily report that benzene reacts violently with iodic acid and sulfuric acid, and after addition of water, a solid compound precipitates out, which was not closer investigated". Mason and Race (Ref. 3, footnote in p. 1723) commented the first German attempt to prepare $\mathrm{PhIO}_{2}$ from benzene as follows: "It does not appear that the experiment was followed up either then or after 1894, when the iodoxy- and the iodonium group were discovered".

2. Masson, I; Race, E.; Pounder, F. E. The Iodoxy-group and its Relations. J. Chem. Soc. 1935, 16691679.

3. Masson, I.; Race, E. The Direct Conversion of Iodic Acid and Aromatic Hydrocarbons into Iodonium Compounds. J. Chem. Soc. 1937, 1718-1723.

4. (a) Beringer, F. M.; Drexler, M.; Gindler, E. M.; Lumpkin, C. C. Diaryliodonium Salts. I. Synthesis. J. Am. Chem. Soc. 1953, 75, 2705-2708. (b) Krowczyński, A.; Skulski, L. p-Iodo-Nmethylacetanilide and its Polyvalent Iodine Derivatives. Polish J. Chem., 1993, 67, 67-70.

5. Beringer, F. M.; Falk, R. A.; Karniol, M.; Lillien, I.; Masullo, G.; Mausner, M.; Sommer, E. Diaryliodonium Salts. IX. The Synthesis of Substituted Diphenyliodonium Salts. J. Am. Chem. Soc. 1959, 81, 342-351.

6. Ciustea, G.; Panescu, A. New synthetic routes in the chemistry of the organic iodine compounds (in Roumanian). Rev. Chim. (Bucharest) 1969, 20, 216; [Chem. Abstr. 1969, 71, 123755].

7. Skulski, L. Organic Iodine(I, III, and V) Chemistry: 10 Years of Development at the Medical University of Warsaw, Poland (1990-2000). Molecules 2000, 5, 1331-1371. Avail. at URL: http://www.mdpi.org/molecules/papers/51201311.pdf

8. Rudzki, P. An attempt of the direct iodylation of arenes. M. Sc. Thesis, Faculty of Pharmacy, Medical University of Warsaw, Poland, 2003 (in Polish).

9. Lulinski, P.; Sosnowski, M.; Skulski, L. A Novel Aromatic Iodination Method, with Sodium Periodate Used Alone as the Iodinating Reagent. Paper presented at the $7^{\text {th }}$ Electronic Conference on Synthetic Organic Chemistry (ECSOC-7, http://www.mdpi.net/ecsoc-7), November 1-30, 2003 (paper A013). Submitted for publication in Molecules.

10. Dictionary of Organic Compounds, $6^{\text {th }}$ ed.; Chapman \& Hall: London, 1996.

11. Kazmierczak, P.; Skulski, L.; Kraszkiewicz, L. Syntheses of (Diacetoxyiodo)arenes or Iodylarenes from Iodoarenes, with Sodium Periodate as the Oxidant. Molecules 2001, 6, 881-891. Avail. at http://www.mdpi.org/molecules/papers/61200881.pdf

12. Kraszkiewicz, L.; Skulski, L. Optimized syntheses of iodylarenes from iodoarenes, with sodium periodate as the oxidant. Part II. ARKIVOC (Gainsville, FL, USA) [online computer file] 2003, (vi), 120-125. Avail. at http://www.arkat-usa.org/ark/journal/2003/Varvoglis/AV-657A/AV657A.htm

13. Groweiss, A. Use of Sodium Bromate for Aromatic Bromination: Research and Development. Org. Process. Res. Dev. 2000, 4, 30-33. See also: (a) Harrison, J. J.; Pellegrini, J. P.; Selwitz, C. 
M. Bromination of Deactivated Aromatics Using Potassium Bromate. J. Org. Chem. 1981, 46, 2169 - 2171, and references therein; (b) Yamaoka, Y. Preparation of 1-bromo-3-nitrobenzene. Jpn. Kokai Tokkyo Koho JP 11 228,505 [99 217,344], 10 Aug 1999; [Chem. Abstr. 1999, 131, 144408].

Sample Availability: Available from the authors.

(C) 2005 by MDPI (http://www.mdpi.org). Reproduction is permitted for noncommercial purposes. 